\title{
Managerial Decision-Making Oriented Towards Achieving Results
}

\author{
Irina Gennadyevna Sevastyanova ${ }^{1} \&$ Vasiliy Nikolaevich Stegniy ${ }^{1}$ \\ ${ }^{1}$ Perm National Research Polytechnic University, Russia \\ Correspondence: Irina Gennadyevna Sevastyanova, Perm National Research Polytechnic University, Komsomol \\ avenue, 29, Perm, 614900, Russia. E-mail: socio@pstu.ru
}

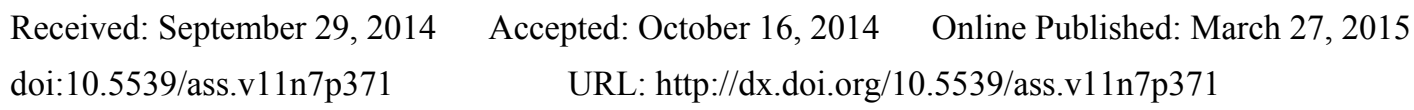

\begin{abstract}
This article identifies the major trends in the development of modern organizations. The article examines organizational issues in effective managerial decision-making; describes model decision-making representations, which integrate the concept, techniques, and practical recommendations; brings to light the social factors influencing managerial decision-making; identifies the key issues in innovation decision-making; provides a rationale for the need to delegate powers for fast decision-making in a dynamic environment; concretizes the potentialities of organizations that employ the decentralization experience in managerial decision-making; brings to light the need for a match between powers and responsibility. The article concludes that the success of organizations depends on making decisions as warranted by specific circumstances.
\end{abstract}

Keywords: managerial decision, decision-making models, individual and group decisions, personal and professional potential, decentralization, delegation and transfer of powers

\section{Constructing Modern Models for Managerial Decision-Making}

The acceleration of the pace of technological changes, intensification of international competition, loosening of market regulation, political instability, and other factors have conditioned the formation of a new business climate. Dramatic changes in the modern business environment facilitate changes in conditions for the operation of organizations.

Orientation towards a more effective use of scientific/technological, investment, and financial resources today makes firms focus on structures that reflect modern trends in the development of organizations (Meleanca, 2013). Such structures are characterized by reduction in management levels, overall reduction in the number of upper and middle management executives, creation of a more flat organizational structure, and raising the status of personnel.

The transition to new relations and new conduct impacts the system of responsibility for making managerial decisions as well. On a correctly made decision depends not only the organization's future activity but its social and psychological climate. Therefore, there ought to be present in decision-making processes a mechanism for managing personnel, which will incorporate motives, stimuli, precepts, values, and norms.

One should keep in mind that decision-making processes are integrated, synthetic. They retain regulative orientedness towards actualizing and achieving results. Besides, amid constantly changing external and internal environment parameters, such as the stiffening of competition and the energetic recession, introduction of new technological and economic standards and safety norms, increase in conflicts between superiors and subordinates, we witness a high variability of managerial decision-making (Fogli \& Guida, 2013).

Managers have to deal with programmed and non-programmed decisions. Rules for making programmed decisions formulated once can be applied in response to regularly repeated organizational issues. Non-programmed decisions have to do with unique, badly defined, or poorly structurized situations (Mescon, Albert, \& Khedouri, 2006).

The development and prosperity of companies interested in generating and sustaining innovation cannot be possible without managers who are capable of making effective non-programmed decisions as part of their wide area of executive duties (Swami, 2013). However, many decisions made in conditions of risk, uncertainty, and unpredictability do not ensure achieving desired results. Only the quest for creative ways of forecasting and 
overcoming the incompleteness, inconsistency, and unobviousness of information can enable one to work out tenable scenarios for discussing alternative variants.

The existing classic, administrative, and political models for decision-making provide managers with choice, which depends on individual and group preferences, the programmability of a decision, and the extent of risk and uncertainty characteristic of it (Duft, 2010). The value of the classic model lies in its helping managers who make decisions to be more rational in working out clear principles and rules that can be applied on a coordinated basis. It is adequate to decisions that meet the economic interests of the organization the most, when managers have access to relevant information, which enables them to gauge events' likelihood of occurrence.

The administrative model focuses on organizational factors and reflects the real process of quick possible actions that can ensure the resolution of current issues. When human, information, and material resources are limited, it is expedient to use a balanced approach, considering rationality and intuition as important components to effective decision-making. This is the way managers sometimes look for alternative solutions to integrated issues until they find that which ensures a satisfactory result.

The political model is useful for making group non-programmed solutions when managers do not have a single opinion on a specific objective or line of conduct provided that differences and conflicts on the priority ranking of issues and their solutions are considered normality. When results are unpredictable, managers can succeed in getting a backing for a particular objective through forming coalitions. Discussions, negotiations, and mutual consultations in the process of informal meetings with other executives enable several managers to make their contribution in decision-making and succeed in getting variants proposed by them adopted.

\section{Social Factors Affecting the Managerial Decision-Making Process}

In reality, the overwhelming majority of managerial decisions is combinatory and incorporates components of both the individual and group choice. The comprehension of issues and identification of current trends and situations brings about new methods for resolving them as well. One of the important effects of the decision-making process is the fact that the manager is under the influence of such psychological factors as social precepts, experience, and personal values (Romashev \& Romashev, 2002). The manager can never be sure that a particular method or way, no matter how well it works, is "right" a priori. Therefore, it is no surprise that methods used in decision-making vary from spontaneous to high-technology.

The need for managerial decision-making is normally associated with an issue or a favorable opportunity, the comprehension of which requires the monitoring of the external and internal environment. Managers start making mistakes if they take up the development of solution variants without having first thoroughly investigated the causes behind the emergence of the issue. Practice confirms that insufficient search for alternatives is the primary reason behind poor relations within organizations.

In this case it comes about the management culture that defines the socio-organizational nature of the decision-making effectiveness (Figure 1) (Kurbatova, 2008).

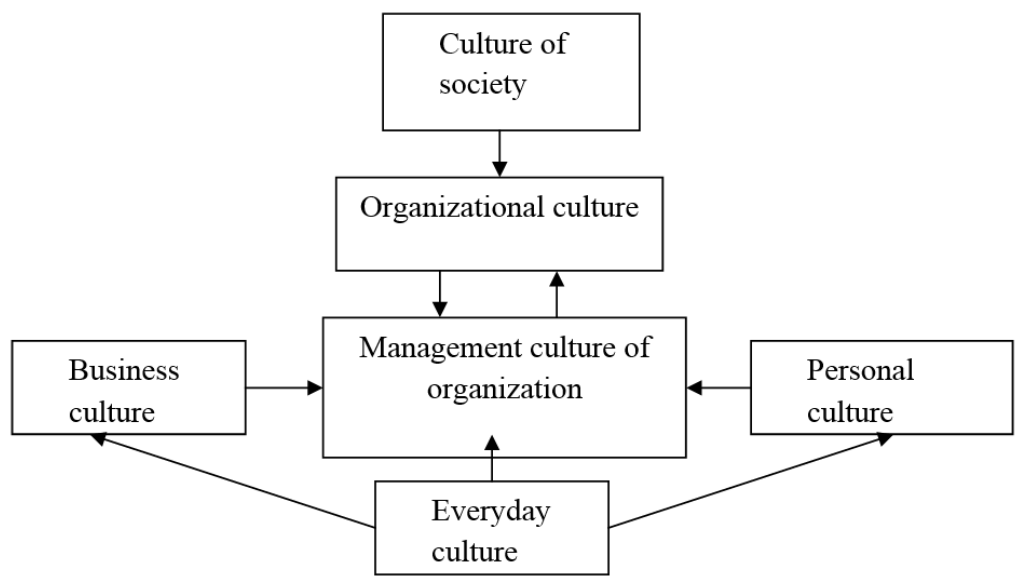

Figure 1. Structural-functional model of management culture of the organization

Decisions in every given case depend on the results of gains and costs analysis. The need for assessing one's chances of success in making non-programmed decisions makes managers choose a variant that is associated 
with minimum risk and uncertainty. They can rely on their intuition and experience. The right choice is possible in being oriented exclusively towards objectives and values as well.

The ultimate success of a chosen alternative depends on resources needed for putting one's plans into practice, as well as the ability and desire to implement the decision made. When employees see that managers do not forget about their decisions and trace the process of their implementation, they become more inclined to positive actions.

The constant assessment of results and feedback help see how successfully a decision has been implemented and whether it has made it possible to attain the goals set. A failed decision can trigger a new analysis of the issue, assessment of alternatives, and choice of a new alternative. In such cases, consistent appraisal of several alternatives, each of which can ensure some improvement, creates conditions for transforming the issue into favorable opportunities.

Therefore, it should be understood that the managerial decision making process is carried out in four areas (Figure 2) (Kurbatova, 2008).

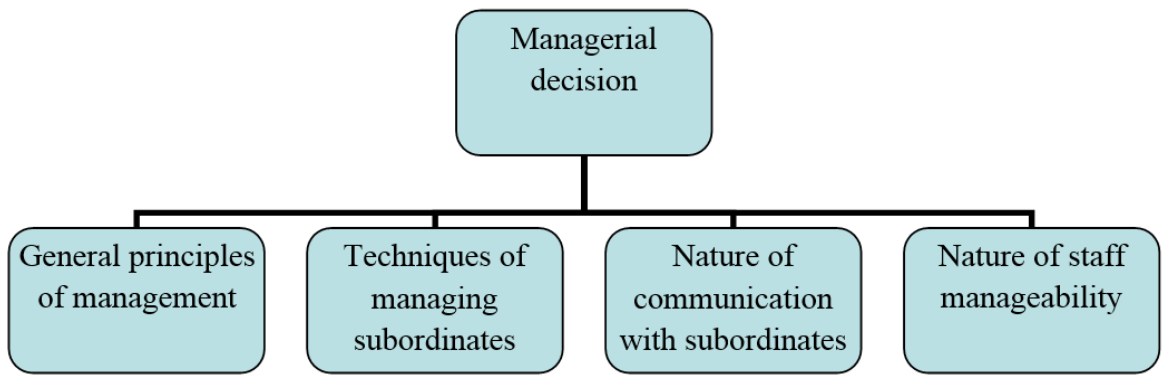

Figure 2. Social and organizational space of managerial decision

The growth of the information sector complicates the procedure for making effective decisions. This is one of the reasons power delegation is becoming increasingly crucial to the management of the decision-making process. Companies keen on creating innovation products are getting convinced in practice that the dynamic, turbulent business environment requires high speed processing of vast amounts of information and expeditious reacting to external impacts (Sevastyanova, Stegniy, \& Sposib, 2010). In these conditions, there is potential in the style of governance that involves subordinates in the decision-making process. The decision-making focus shifts to where issues arise and where information comes from. Effective managers, learning lessons from transformations taking place in modern organizations, use power delegation as a means of individual and organizational learning, which is crucial to fast decision-making in a dynamic environment.

Thus, the effectiveness of taking a management decision is affect not only by the organizational factors. Selecting a management model is directly related to the personality of manager and management culture of organization.

\section{Modernizing the Decentralization Principle as a Condition for Boosting the Effectiveness of Managerial Decisions Made}

Power delegation is grounded in the principle of decentralization, whereby the decision-making process shifts downwards to executives who are closely associated with specific issues (Norman \& Reed, 2010). Renouncing existing centralization stereotypes, where directives come down from above based on the "commands and control" system, and switching to group issue resolution creates conditions for integrating powers and ensures the basis for adapting structures to changing conditions.

The decentralization experience in management structures attests to a number of advantages of such organizational restructuring. The use of a flat organizational structure facilitates streamlining executives' professional skills, boosting the creative nature of managerial efforts and boosts one's aspiration to contribute to the growth and development of the company. The system of effective non-formalized communicative channels and procedures for communicating with people has been universally recognized. Considerable numbers of employees in various organizations agree to work more and better provided they are given an opportunity to take part in resolving issues related to their work. 
In high-technology industries, where the pace of competitive and technological changes is high, favorable opportunities are short-lived, while the availability of full information is rather an exception. Management structures that are focused from the start on the need to follow the traditional order of things impede the process of companies' adaptation to the needs of the era of information overload.

Most innovative decisions under vertical organizational structures are made not on the basis of available information and logic but rather politics and emotions. Here, the priority rests with one's ability to form unions, attract attention to one, enlist the support of senior management, as well as channel the decision-making process in a direction one considers advantageous to one's interests. And such a rational element in decision-making as information becomes just a tool for backing political decisions. Very often, senior management sees its objective in just identifying shortcomings under a plaque saying "Information credibility check" or "Proposal consideration".

A bad service is also done by the fact that companies pay more attention to the process - not the result - of their activity. In such conditions, the result is the declining pace of making decisions on the corporate level, the diminishing extent of responsibility for making decisions, and promoting proposals not associated with risk. Leaving out of account the importance of delegating powers or what is needed for boosting its effectiveness, many executives fail exactly at a time when their organizations are becoming bigger.

Considering delegation as one of the elements of forming organizational management structures, one needs to come up with an agreeable ratio between centralization and decentralization depending on such factors as the size of the organization, production technology, and the external environment. The decision-making process on the lower levels ought to complement the vertical system of management and be part of daily decision-making processes.

In case of transferring powers to the lower levels without securing the corresponding resources, there can be a use in activity in the form of recommendations, information accumulation, and working out counsel. A higher extent of decentralization, which is considered as a transfer of the decision-making process into the lower echelons, implies that different organizational functions are considerably influenced by decisions made on the lower levels. Flat organizational structures with maximum decentralization create conditions for the activity of executives that are more professionally prepared and diminish the administrative distance between the levels of governance.

Decentralization does not mean removing control. Organizations with fewer levels of governance and wider control coverage are found to be more flexible and dynamic than centralized establishments. Well-defined control over the results of work is one of the major factors to effective delegation. Prior to delegating responsibility for resolving an issue and corresponding powers, one ought to have a clear idea of what results to expect from one's subordinates and when these results should be attained (Armstrong, 2009).

Delegation often turns out ineffectual due to difficulties overcoming such obstacles that have become deeply rooted in human conduct as worries about one's position, fear of risk, lack of confidence in oneself, or the inability to entrust a task one is responsible for to someone else. Besides, in reality most executives prefer to have employees who are a reflection of themselves. Consequently, there is danger that delegation "tied" to the style and work program of the manager and one's superior will prove ineffective. The art of transferring powers in large part depends on one's susceptibility to new ideas, readiness to let a lower echelon of governance handle a task, ability to trust employees, and aspiration to administer general control.

The growth of the social role of man and complication of technical-economic conditions for the operation of organizations dictate the need for transition from individual decision-making methods to group ones retaining the hierarchy parameter (Laux \& Liermann, 2006). High uncertainty within the environment intensifies the aspiration of organizations using non-routine technology towards decentralization and delegation of decision-making powers.

Power delegation is not a way to dodge responsibility. Efficient delegation requires a match between powers and responsibility. Superiors ought to delegate to subordinates powers sufficient for fulfilling all tasks they have taken on responsibility for. A top official, in turn, continues to bear responsibility for the actions of one's subordinates. This form of dividing managerial labor makes things easier for the executive but does not relieve one of the obligation to make a final decision.

If delegation is implemented in line with the expected result and well-defined distribution of powers and responsibility across the lower levels of governance, this will be the best way of boosting the effectiveness of decision-making by executives in the middle and upper levels of management. Unfortunately, in practice the 
match principle is often violated, which results in employees' refusal to take on additional powers. Initiatives related to efforts on "building" mutual relations, identifying what's primary, and a clear understanding of the essence of distribution of powers, responsibility, and obligations are guarantors of effective decision-making.

\section{Conclusion}

There is no "correct" answer in effective decision making. This is associated with that numerous situational changes and all the functions of the management process cannot be considered independent from each other (Cetindamar, Phaal, \& Probert, 2010). In making real decisions, many factors have to be taken into account, and the manager ought to see the entire situation as a whole.

Managerial decision-making ought to be viewed not only from the standpoint of managerial effectiveness and organizational productivity but also that of the manager's personal and professional potential, as well as choice of conduct. Among conduct-related issues related to many psychological and organizational characteristics of managerial activity, we should point up a considerable portion of decisions being of a group nature, which lays a solid groundwork for "shifting" decision-making to the shoulders of others; a high degree of responsibility, which is a powerful stimulus for avoiding a decision; the vagueness of the manager's status as a reason to stay away from "hard" decisions.

The preference is with decision-making methods that best comport with the goals of the organization, its specific characteristics, and, above all, the interests of people. Organizations that have been successful for a long time make decisions that are dictated by specific situations, while the professionalism of their managers helps foster a stimulating environment for implementing them.

\section{References}

Armstrong, M. (2009). Human Resource Management Practice (p. 848). SPb.: Piter.

Cetindamar, D., Phaal, R., \& Probert, D. (2010). Technology Management: Activities and Tools (p. 274). Palgrave Macmillan, New York.

Duft, R. (2010). Management (p. 800). SPb.: Piter.

Fogli, D., \& Guida, G. (2013). Knowledge-centered design of decision support systems for emergency management. Decision Support Systems, 55(1), 336-347.

Kurbatova, L. N. (2008). The innovative management functions as a characteristic of management culture. Development of innovative entrepreneurship in the modern economy: Materials of the Interregional Scientific and Practical Conference, Perm, April 22-23, 2008 (pp. 164-169). GOU VPO State Technical University of Perm. Perm.

Laux, H., \& Liermann, F. (2006). Basics of the organization: The control of decisions as fundamental problem. The Betreibswirtschaftslehre (Fundamentals of Organization: The Management of Decision Making) (p. 600). M.: Delo i Servis.

Meleanca, R. (2013). Will Decision Management Systems Revolutionize Marketing? Procedia - Social and Behavioral Sciences, 92, 523-528.

Mescon, M. H., Albert, M., \& Khedouri, F. (2006). Management (p. 704). Delo.

Norman, T. J., \& Reed, C. (2010). A logic of delegation. A Logic of Delegation. Artificial Intelligence, 174(1), $51-71$.

Romashev, O. V., \& Romashev, L. O. (2002). The Sociology and Psychology of Management: A College Textbook (p. 512). M.: Ekzamen.

Sevastyanova, I. G., Stegniy, V. N., \& Sposib, A. G. (2010). Innovative Project Team Motivation. Innovatsii, 12(146), 95-99.

Swami, S. (2013). Executive functions and decision making: A managerial review. IIMB Management Review, 25(4), 203-212.

\section{Copyrights}

Copyright for this article is retained by the author(s), with first publication rights granted to the journal.

This is an open-access article distributed under the terms and conditions of the Creative Commons Attribution license (http://creativecommons.org/licenses/by/3.0/). 